\title{
Numerical simulations to determine the influence of mould design on ice-templated scaffold structures
}

\author{
Anke Husmann ${ }^{1}$, Kendell Pawelec ${ }^{1,2}$, Clare Burdett $^{1}$, Serena Best $^{1}$, Ruth Cameron ${ }^{1}$ \\ 1. Cambridge Centre for Medical Materials, Department of Materials Science and Metallurgy, University of Cambridge, \\ Cambridge, UK. 2. FUJ IFI LM Manufacturing Europe, Netherlands.
}

Correspondence: Anke Husmann. Address: Cambridge Centre for Medical Materials, Department of Materials Science and Metallurgy, University of Cambridge, 27 Charles Babbage Road, Cambridge, CB3 0FS, UK. Email: ah492@cam.ac.uk

Received: June 28, 2015

DOI : $10.5430 /$ jbei.v1n1p47

\author{
Accepted: July 30, 2015 \\ Online Published: August 10, 2015 \\ URL: http://dx.doi.org/10.5430/jbei.v1n1p47
}

\begin{abstract}
In recent years, there has been a shift from traditional cell culture on two-dimensional substrates towards the use of three-dimensional scaffolds for tissue engineering. Ice-templating is a versatile tool to create porous scaffolds from collagen. Here we discuss specific considerations for the design of moulds to produce freeze dried collagen scaffolds with pore sizes of around $100 \mu \mathrm{m}$, a range that is relevant to tissue engineering. A numerical model of heat conduction, implemented in COMSOL Multiphysics ${ }^{\circledR}$ version 5.0, calculated the temperature contour lines and heat flow vectors during cooling for a variety of mould geometries and materials. We show how temperature distribution within moulds determines the resulting pore structure of the scaffolds by regulating ice growth, and we validate our simulation against experimental results. These simulations are especially useful when working with moulds that contain volumes of more than $1 \mathrm{~cm}$ in each direction.
\end{abstract}

\section{Key words}

Scaffold, Collagen, Ice-template, Pore architecture, Tissue engineering, Numerical simulation

\section{I ntroduction}

Ice-templating techniques can be used for many material systems, such as polymers and ceramics, for applications as diverse as pharmaceutical drying, continuous flow catalysts, and tissue engineering scaffolds ${ }^{[1-5]}$. Producing collagen scaffolds by ice-templating has proven to be a very successful technique for tissue engineering, enabling cell culture to move from two-dimensional substrates towards three-dimensional scaffolds. They can be used for maintenance of cell phenotype in long term culture, creation of more effective drug delivery devices, and studies of whole tissue morphogenesis ${ }^{[6-8]}$.

The pore architecture of the scaffold influences many of their characteristics such as mechanical properties ${ }^{[9]}$ and fluid flow as well as the biological influence exerted by the framework ${ }^{[6,10]}$. Both, isotropic structures, those with equiaxed, spherical pores throughout, and anisotropic structures, which possess regions of aligned porosity, can be created via ice-templating. The properties of these scaffolds can be further tuned with chemical composition and cross-linking and have already demonstrated success in the regeneration of tendon, skin and nerve ${ }^{[4,10-13]}$. 
In ice-templating, three-dimensional scaffold structures are created during the solidification of a water-based suspension. Within the suspension, ice crystals first nucleate, then grow, rejecting the solute to the volume between crystals. Once the ice template is formed, it is removed via sublimation during the drying stage, leaving behind a porous three dimensional structure which is the inverse of the ice template. In order to tailor the scaffold structure, the growth of the ice template must be controlled, which is, in turn, influenced by the two phases of crystallization: ice nucleation and growth ${ }^{[14]}$. In addition, features of the scaffold can also be linked to the annealing process during solidification which we have addressed before ${ }^{[15]}$.

Creating a defined pore architecture requires control over when and where ice nucleates within the aqueous slurry, and how it grows from the initial nucleation point in a given mould. To date, mould design within the tissue engineering community has remained limited to trial and error with previous attempts in the literature focusing on utilizing icetemplating moulds to create aligned pores ${ }^{[16,17]}$. Recently, Muzzio et al. ${ }^{[18]}$ have shown that finite element analysis can be a very useful tool when modelling heat flow in vials for freeze drying. More complex numerical approaches are successfully used within the crystal growth community to simulate and optimise bulk crystal growth in furnaces (see for example ${ }^{[19,20]}$, a related, but not identical problem.

The aim of our work is to construct a numerical model which connects the local thermal environment for ice growth by freeze drying to pore architecture of the resulting scaffold and furthermore can be implemented by other researchers. Our computer program, implemented in COMSOL Multiphysics ${ }^{\circledR}$ version 5.0, calculates the temperature distribution within the mould and slurry during cooling by solving the heat conduction problem with given boundary conditions. By changing the thermal properties and geometric design of the ice-templating mould, we can vary the temperature distribution within the slurry. The simulations have been validated against experimental work to link the scaffold pore structure created by various moulds to design parameters, gaining an in-depth understanding of the underlying principles in mould design. This method is especially useful when working with moulds that contain volumes of more than $1 \mathrm{~cm}$ in each direction and are cooled in a commercial freeze dryer where cooling occurs slowly.

\section{Methods and materials}

\subsection{Setting up the computational model}

The rate of crystal growth in general depends on three physical processes: mass diffusion, flow rate of latent heat away from the liquid/crystal interface and the specifics of the particle attachments at the liquid/crystal interface ${ }^{[21]}$. In the case of the water/ice system, the flow rate of latent heat away from the surface plays by far the most important role ${ }^{[22]}$. We will therefore focus on the thermal aspects of the model.

We are interested in bulk samples with external dimensions of $1 \mathrm{~cm}$ and larger, produced in a freeze dryer. In this case, the overall heat production due to the latent heat outweighs the heat removal along the sides of the mould. As a consequence, two growth phases are established. During phase one, the initial crystal develops very quickly from the nucleation site within the already supercooled water/collagen mixture. Its growth rate only slows down when the water/collagen mixture warms up to melting temperature as a result of latent heat release. Part of this initial ice skeleton may melt directly after this phase if it is in direct contact with water or mould wall at temperatures above the melting temperature ${ }^{[23]}$. The sequential, secondary ice growth, depends on the heat removal through the walls of the container, with crystals growing from the dendritic ice skeleton that had formed during the initial fast growth.

This leads to the following notation for our experiments. Figure 1a shows a schematic of the freeze dryer with sample. We record the temperature as a function of time with thermocouples at various points (1) - (4). The freeze drying process, Figure $1 \mathrm{~b}$, is divided into six stages: the initial cooling stage, a first stage of freezing (I) which is very short $(\Delta t<4 \mathrm{~s})$ and a second stage of freezing (II) which is much longer (30-60 minutes). Once the water/collagen slurry is frozen, it is kept 
cold in a waiting stage. The vacuum is then reduced but the shelf kept at $T_{\text {shelf }}=-30^{\circ} \mathrm{C}$. In the last stage, the ice is sublimed where the shelf temperature is raised to $T_{\text {shelf }}=0^{\circ} \mathrm{C}$ (see Figure 1b).

In our computational model, we calculate the temperature distribution and directional heat flows within the mould and slurry at the time point when a nucleation event occurs, see Figure $1 \mathrm{~b}$. This gives us the thermal environment for the initial fast crystal growth after nucleation that leads to the ice skeleton, as mentioned above.

Ice nucleation in itself is a stochastic event with a high probability within a small temperature range below the melting temperature ${ }^{[24]}$. For our moulds, we have found experimentally that nucleation occurs when the temperature at the base of the slurry is in temperature range between $T_{N}=-4^{\circ} \mathrm{C}$ and $T_{N}=-10^{\circ} \mathrm{C}$.

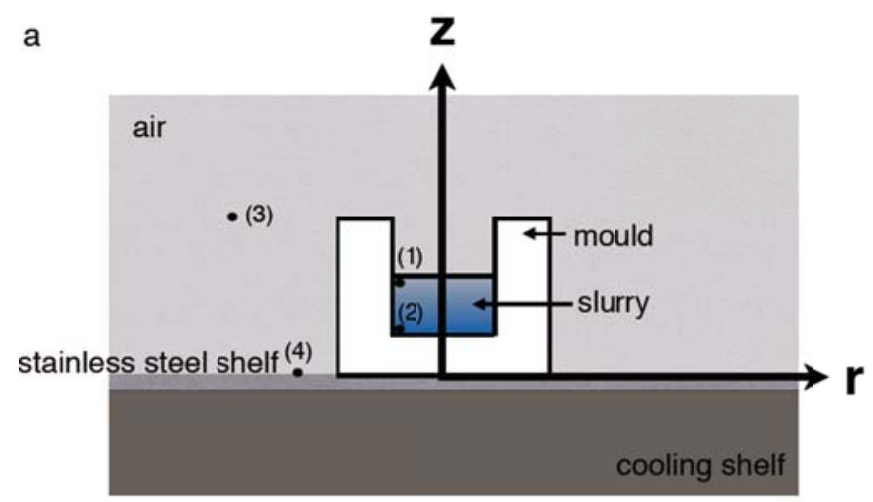

Figure 1. (a) Schematics of the experimental set-up showing the mould in the freezer dryer and indicating the location of thermocouples. (b) Experimental time dependent temperature measurements from the thermocouples.

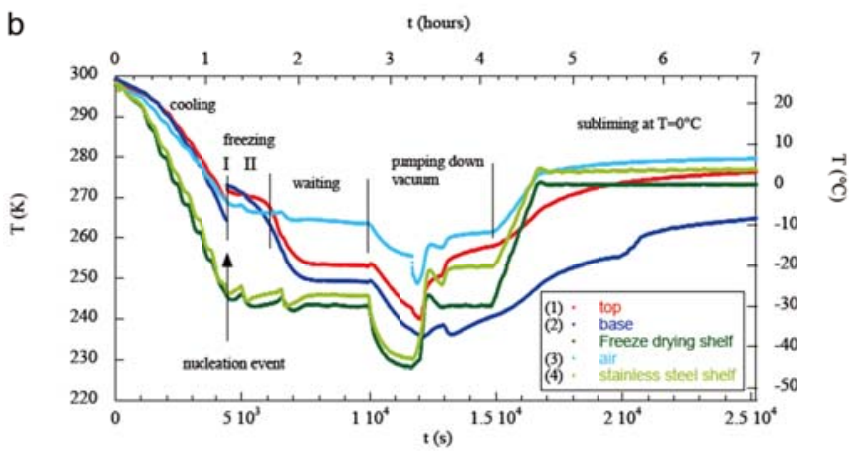

\subsection{I mplementation of the model}

The computer simulation was implemented in COMSOL Multiphysics ${ }^{\circledR}$ version 5.0 using finite element methods to solve for thermal diffusion during cooling. The main equation for this study is the time dependent heat conduction equation: $\rho C_{p} \partial T / \partial t=\nabla \cdot(k \nabla T)$. We did not take heat conduction via convection into account due to the high viscosity of the slurry.

We have used various moulds for our experiments. Our choice of materials were stainless steel and polycarbonate. The metal gives a good thermal link to the thermal bath (freeze dryer shelf) and increases the cooling rate. Polycarbonate has a thermal diffusivity that is comparable to that of water (see Table 1), which leads to slower but more even cooling. We also used combinations of both: an outer metal sleeve for the polycarbonate mould to increase the speed of cooling and an inner metal sleeve to provide a thermal link for the top and the base of slurry along the vertical axis.

The parameters used in the equation for the various materials are listed in Table $1^{[25,26]}$. We have used the values for water from the COMSOL Multiphysics ${ }^{\circledR}$ ver. 5.0 materials library. The addition of $1 \mathrm{wt} \%$ collagen is not expected to change the parameters significantly, see Ref. ${ }^{[27]}$. The heat conduction equation can be re-written using only the thermal diffusivity, $\alpha$ $=k / \rho C_{p}$ (assuming that the thermal conductivity $k$ is isotropic), which is also listed in Table 1 . 
Table 1. Thermal properties of polycarbonate, stainless steel and water

\begin{tabular}{lllll}
\hline Material & $\begin{array}{l}\text { Thermal conductivity } \boldsymbol{k} \\
\mathbf{W} / \mathbf{m ~ K}\end{array}$ & $\begin{array}{l}\text { Density } \boldsymbol{\rho} \\
\mathbf{k g} / \mathbf{m}^{3}\end{array}$ & $\begin{array}{l}\text { Heat capacity } \boldsymbol{C}_{\boldsymbol{p}} \\
\mathbf{J} / \mathbf{k g ~ K}\end{array}$ & $\begin{array}{l}\text { Thermal diffusivity } \boldsymbol{\alpha} \\
\mathbf{m}^{2} / \mathbf{s}\end{array}$ \\
\hline Polycarbonate & 0.12 & 1,200 & 1,250 & $8.0 \times 10^{-8}$ \\
Stainless steel & 15 & 7,900 & 460 & $4.13 \times 10^{-6}$ \\
Water (slurry) & 0.556 & 1,006 & 4,200 & $1.32 \times 10^{-7}$ \\
\hline
\end{tabular}

The moulds were cylindrical with a symmetry axis of rotation at $r=0$. We varied the diameter of the inner space of the moulds: $d=16 \mathrm{~mm}$ and $d=45 \mathrm{~mm}$ (metal), $d=20 \mathrm{~mm}$ and $d=32 \mathrm{~mm}$ (polycarbonate), and $d=16 \mathrm{~mm}$ and $d=20 \mathrm{~mm}$ (combined). The slurry height was kept at $z=15 \mathrm{~mm}$ for comparison between moulds.

Figure 2 shows the moulds with their finite element meshing. The meshing parameter was "finer physics-controlled meshing" (COMSOL Multiphysics ${ }^{\circledR}$ ver. 5.0). The rotational symmetry of the moulds reduces the three dimensional computational problem to a two dimensional one.

\subsection{Experimental set-up}

For the corresponding experiments, a collagen suspension of $1 \mathrm{wt} \%$ was prepared from bovine Achilles tendon, type I collagen (Sigma Aldrich), hydrated in $0.05 \mathrm{M}$ acetic acid. Slurries were homogenised for 30 minutes at 13,500 rpm in an ice water bath (VDI 25, VWR International Ltd, UK), and centrifuged (Hermle Z300) for 5 minutes at 2,500 rpm. Prepared suspensions were poured into various freeze drying moulds.

A stainless steel shelf was placed on the cooling shelf of the freeze dryer to ensure a more even temperature distribution along the cooling shelf (see Figure 1). The moulds with slurry were cooled at a set rate of $0.9{ }^{\circ} \mathrm{C} / \mathrm{min}=0.015{ }^{\circ} \mathrm{C} / \mathrm{s}$, and held for 90 minutes at $-30^{\circ} \mathrm{C}$. It was found that this cooling rate produced pore sizes in the resulting collagen scaffolds that are useful for cell growth ${ }^{[22]}$. The frozen slurries were then lyophilised using a Virtis freeze dryer (SP Industries, USA) at $0^{\circ} \mathrm{C}$ for 20 hours under a vacuum of around $10 \mathrm{~Pa}$. We wrote a LabVIEW ${ }^{\circledR}$ computer program to record the thermocouples with a time resolution of $\Delta t=4 \mathrm{~s}$. This enabled us to establish an upper time limit on the initial freezing phase.

X-ray micro-computed tomography $(\mu \mathrm{CT})$ (Skyscan 1172) scans were taken of the complete scaffolds with a voltage of $25 \mathrm{kV}$, current of $138 \mu \mathrm{A}$. Reconstructions were performed with the software NRecon (Skyscan).

\section{Results}

We have divided our results into three sections. First, we discuss how we obtained boundary conditions for the computational model from experiments. We then discuss results for two different sets of boundary conditions.

\subsection{Boundary conditions}

The temperature near the mould along the shelf is measured and used as the boundary condition at the base of the mould. For a direct comparison between moulds (section 3.2), we used COMSOL's inbuilt ramp function with the following parameters for the ramp function: location $=0$, slope $=-0.0137$ (as measured), cut-off $=-53$, size of transition zones $=300$. We add $T_{\text {start }}=296 \mathrm{~K}$ to the ramp function in the boundary condition. For comparison with experimental results (section 3.3), we used numerical fits to actual measurements.

The boundary between mould and air plays an important role during cooling in the freeze dryer. The air pressure in the freeze dryer during cooling and freezing is typically around $5 \times 10^{4} \mathrm{~Pa}$ after sealing the door. This provides a significant thermal link between the internal space of the freeze dryer and the outside resulting in the air being cooled by the cooling shelf and heated by the outside room. The temperature dependence of the air in the freeze dryer was measured by 
thermocouples at various places. As the thermal diffusivity of air is very high, $\alpha_{\text {air }}=2 \times 10^{-5} \mathrm{~m}^{2} / \mathrm{s}$, heat diffuses very quickly equalising the air temperature within the freeze dryer fairly well. It should be noted that we cool from below which reduces air convection.
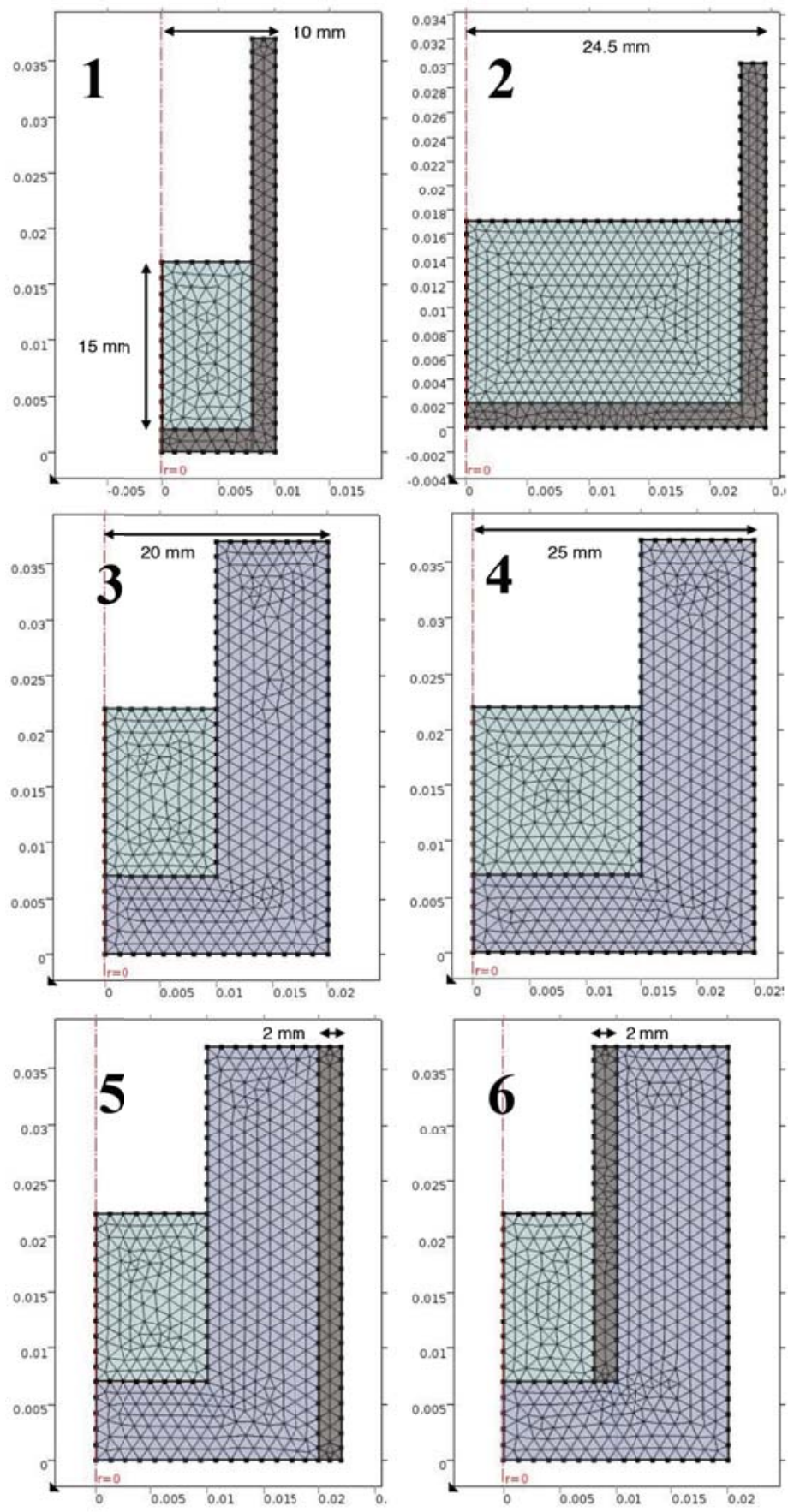

stainless steel

polycarbonate

slurry

Figure 2. Mould geometry and materials of the six different moulds. The meshing used in the simulation is also shown.

Within COMSOL Multiphysics ${ }^{\circledR}$ ver. 5.0, the boundary condition between mould/slurry and air was chosen as "external heat flux". The heat transfer coefficient, $h$, in the heat flux equation for this boundary condition, $q_{0}=h \cdot\left(T_{\text {ext }}-T\right)$, across boundaries is difficult to determine. In the case of gases under natural convection, the value is given to lie between 5 and 
$30 \mathrm{~W} / \mathrm{m}^{2} \mathrm{~K}{ }^{[28]}$. We found that for our stainless steel moulds, $h=30 \mathrm{~W} / \mathrm{m}^{2} \mathrm{~K}$ fits the experimental data better than $h=$ $5 \mathrm{~W} / \mathrm{m}^{2} \mathrm{~K}$, see Figure 3 for the effect of different values for $h$. We therefore used $h=30 \mathrm{~W} / \mathrm{m}^{2} \mathrm{~K}$ in all cases.

Figure 3. We varied the value of the heat transfer coefficient $h$ and compared the resulting time dependent temperature at the top of the slurry (location 1 in Figure 1a) of the simulation with experimental data, obtained in mould 1.

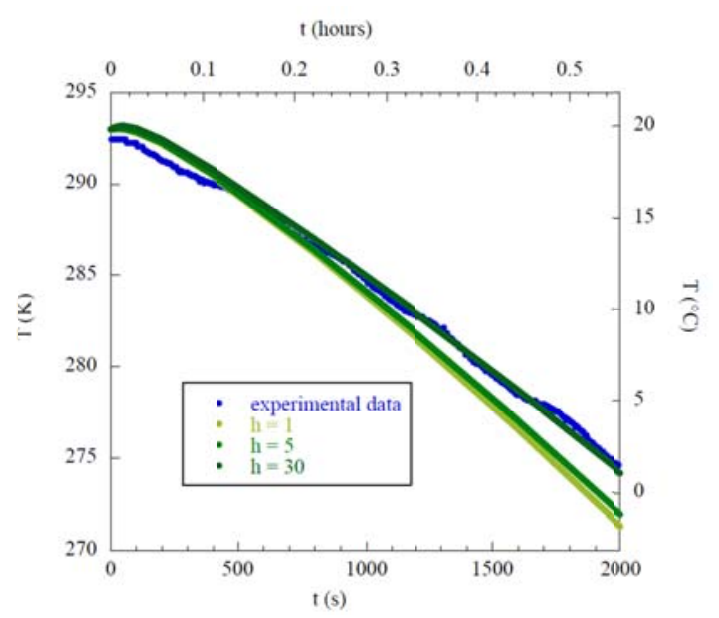

For comparison between moulds (section 3.2), we define $T_{\text {ext }}=T_{\text {air }}$ with a COMSOL inbuilt ramp function, with the following parameters: location $=0$, slope $=-0.00548$ (as determined from experimental data), cut-off $=-25$, size of transition zones $=3500$. We add $T_{\text {start }}=296 \mathrm{~K}$ to the ramp function in the boundary condition. For direct comparison between simulation and experiments (section 3.3), we use actual measurements from experiments.

For the thermal contact between steel and polycarbonate, present in moulds 5 and 6, we used the Cooper-MikicYonvanovich correlation boundary condition ${ }^{[29]}$ and parallel-plate gap gas conductance with the following parameters: contact pressure of $1 \mathrm{~atm}$, mircohardness of $0.2 \mathrm{GPa}$ and a gas pressure $0.5 \mathrm{~atm}$ (in units used by COMSOL Multiphysics ${ }^{\circledR}$ ver 5.0).

\subsection{Comparison between different moulds}

For Figure 4 and 5, we have used the same boundary conditions for all moulds. The boundary conditions were chosen to match the experimental data from mould 3. The simulation was stopped when the coldest point of the slurry reaches $T=$ $267 \mathrm{~K}\left(-6.15^{\circ} \mathrm{C}\right)$. This coincides with the time when a nucleation event had occurred in mould 3 . This enables us to compare the thermal profiles of the different moulds under the same conditions.

First, we considered moulds made from stainless steel which is a material traditionally used for freeze drying due to its good thermal conductivity and its compatibility with biomaterials. The cooling rate of the slurry at the base is relatively fast. The thermal distribution and heat flow, as indicated by the arrows, at the time of nucleation is shown in Figure 4(a)(b), for both moulds, at time $t=2,180 \mathrm{~s}$ (36.3 $\mathrm{min})$.

The temperature contour lines in the small container are fairly horizontal and most of the cooling occurs through the base. However, in the mould with the larger diameter, the contour lines indicate that the cooling of the slurry also occurs through the sides of the container. This leads to contour lines with strong vertical components near the edge.

The second set of moulds were made from polycarbonate. We have already published some work on the effect of different filling heights ${ }^{[30]}$ in the smaller of the two moulds. Polycarbonate has, as mentioned above, see Table 1 , very similar thermal diffusivity to water. As can be seen in Figure 4(c)(d), this leads to almost parallel temperature contour lines within the slurry with heat flow through the base. The base of the slurry, however, cools more slowly than in the stainless steel moulds; nucleation here occurs after (c) $t=4,093 \mathrm{~s}(68.2 \mathrm{~min})$ and (d) $t=4,134 \mathrm{~s}(68.9 \mathrm{~min})$. 
(a)

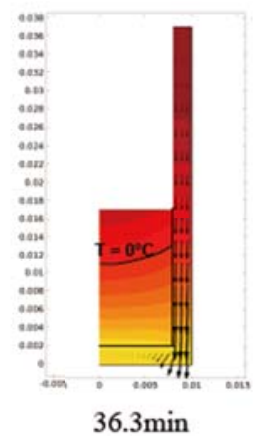

(c)

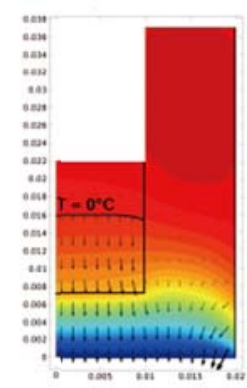

$68.2 \mathrm{~min}$

(e)

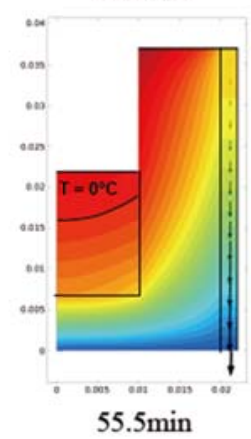

(b)

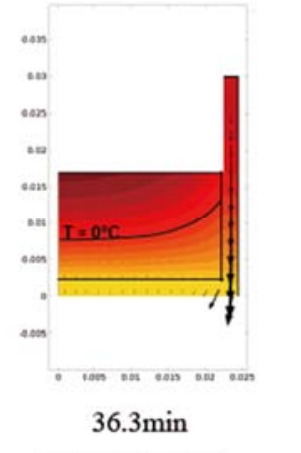

(d)

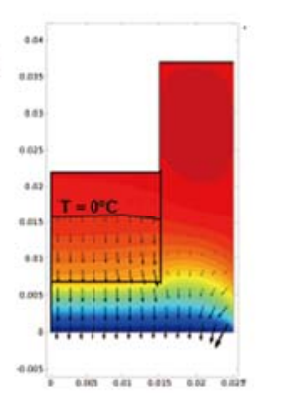

$68.9 \mathrm{~min}$

(f)

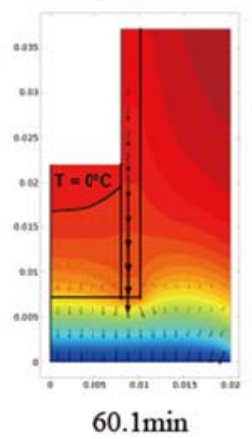

$\mathrm{T}(\mathrm{K})$

$\Delta 278$

$\quad \times 10^{2}$
-2.78
-

$\times 10$
-2.78
-2.77

$-2.76$

2.75
-2.74

$-2.74$

$-2.72$

$-2.71$

$-2.7$

- 2.69

$-2.68$

-2.67
-2.66

]$_{2.65}^{2.66}$

-2.65
-2.64

$\square_{-2.63}^{2.64}$

${ }_{-2.61}^{2.62}$

${ }_{-2.6}^{2.61}$

$-2.59$

$-2.58$

$-2.57$

2.56
-2.55

$-2.54$

$-2.53$

2.52
-2.51

- 2.51

$-2.49$

$-2.48$

$Z_{-2.47}^{2.48}$

$-2.46$

$=2.45$

$\square_{2.43}^{2.44}$

Figure 4. COMSOL simulations for all six moulds using the same boundary conditions. Temperature contours and the magnitude and direction of heat flow are shown when the coldest part of the slurry reaches $T=267 \mathrm{~K}\left(-6.15^{\circ} \mathrm{C}\right)$.

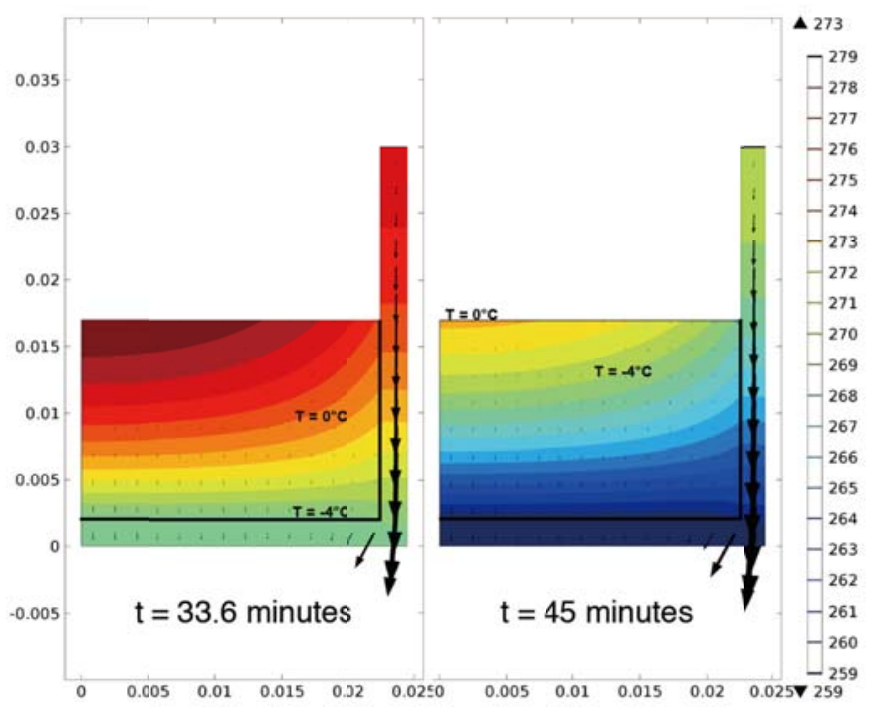

Figure 5. Temperature contours and the magnitude and direction of heat flow in the large stainless steel mould at two different times 
Thirdly, we combined both materials within one mould. A stainless steel sleeve outside the smaller polycarbonate mould leads to a faster cooling rate, leading to $T=267 \mathrm{~K}$ being reached after $t=3,331 \mathrm{~s}(55.5 \mathrm{~min})$. The temperature contour lines are similar to the metal mould across the slurry and polycarbonate mould, see Figure 4(e). The walls of the polycarbonate mould are fairly thick and contain most of the volume with temperature contour lines that have a large vertical component. As a last step, we inserted a stainless steel sleeve as an insert into the smaller polycarbonate mould, see Figure 4(f). This led to the smallest temperature gradients within the slurry for all of the moulds shown here, and it took $t=3,604 \mathrm{~s}(60.1$ $\min$ ) to cool to the temperature $T=267 \mathrm{~K}$.

\subsection{I mportance of time of nucleation}

Nucleation events occur stochastically. In our case, we found experimentally that the nucleation events occurred between $-4^{\circ} \mathrm{C}$ and $-10^{\circ} \mathrm{C}$. It seems that, often, when a mechanical valve switches in the freeze dryer, nucleation occurs due to the mechanical vibrations providing enough energy to trigger an event.

In Table 2, we compare the time difference between the point at which the coldest point in the slurry reaches $T=-4^{\circ} \mathrm{C}$ in our simulation and the point at which the warmest point reaches $T=0^{\circ} \mathrm{C}$. The first point indicates the time at which nucleation first becomes possible. The second point indicates the time at which the whole slurry is supercooled below the melting temperature, and ice growth becomes possible throughout the whole slurry. This time interval is crucial when designing a mould to create isotropic structures. A nucleation event between the two time points leads to anisotropic scaffolds while nucleation after the second time point leads to isotropic scaffolds.

Table 2. Time difference between the point at which the coldest point reaches $T=-4^{\circ} \mathrm{C}$ and the point at which the warmest point reaches $T=0^{\circ} \mathrm{C}$. For explanation of the relevance of the two time stamps see text

\begin{tabular}{lllll}
\hline Mould & Mould material & $\begin{array}{l}\text { Time at which coldest point } \\
\text { reaches } \boldsymbol{T}=\mathbf{- 4}^{\circ} \mathbf{C}(\mathbf{m i n})\end{array}$ & $\begin{array}{l}\text { Time at which warmest point } \\
\text { reaches } \boldsymbol{T}=\mathbf{0}^{\circ} \mathbf{C}(\mathbf{m i n})\end{array}$ & $\begin{array}{l}\text { Time difference } \\
(\mathbf{m i n})\end{array}$ \\
\hline 1 & Stainless steel & 33.7 & 40.8 & 7.1 \\
2 & Stainless steel & 33.6 & 45.0 & 11.4 \\
3 & polycarbonate & 63.3 & 72.5 & 9.2 \\
4 & polycarbonate & 64.2 & 72.4 & 8.2 \\
5 & both & 52.2 & 58.3 & 6.0 \\
6 & both & 56.0 & 62.0 & 6.0 \\
\hline
\end{tabular}

We include simulation results for the large stainless steel mould, mould 2, at different time stamps to show the time development of the temperature contour lines. As can be seen around the time of nucleation, the temperature gradients within the slurry remains very similar but the temperature contour line of the melting temperature $T=0^{\circ} \mathrm{C}$ moves within the slurry (see Figure 5).

\subsection{Comparing experimental results with simulations}

In Figure 6, we have compared simulations with experimentally obtained scaffolds. This was enabled by choosing experimentally obtained boundary conditions for each mould. In addition, we adjusted the time of nucleation to match that of the experiments in which the scaffolds were fabricated.

Water/collagen slurry was freeze-dried in the six moulds using the freezing protocol mentioned in the method section. After the experiment, $\mu \mathrm{CT}$ pictures were taken from scaffolds made in mould 1 to 6 , see Figure 6 (a-f), and for $\mu \mathrm{CT}$ settings see the method section. While the pores in mould 2, 3 and 4 are anisotropic (see Figure 6(b), (c) and (d)), the pores in mould 1, 5 and 6 (see Figure 6(a), (e) and (f)), are isotropic. When compared with the thermal profiles, now using the individual experimental cooling boundary conditions, it can be seen that an ice front is established when the contour of the melting temperature (for DSC data of our slurries see ${ }^{[15]}$ ) lies within the slurry at the point of a nucleation event. An ice front leads to anisotropic pores. We can also predict the direction of the ice flow. As the temperature of the slurry above the 
melting line is warm and the heat flow is through the colder part of the slurry, the ice crystals will partially melt after the initial freezing and the ice front will establish below the initial melting temperature line ${ }^{[31]}$.

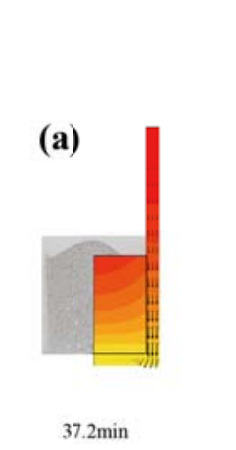

(c)

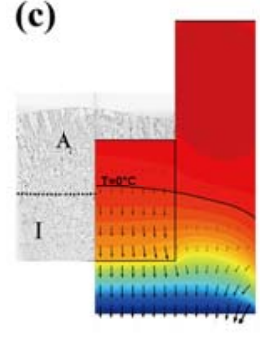

(e)

Figure 6. COMSOL simulations and microCT pictures for all six moulds using individually experimentally measured boundary conditions for each mould. Temperature contours and the magnitude and direction of heat flow are shown when the coldest part of the slurry reaches the temperature measured at point (2) (see Figure 1a) when nucleation occurs (see Figure 1b for definition). The dotted line in (b), (c) and (d) delineates the boundary between isotropic (I) and anisotropic (A) pore structure.
$68.2 \mathrm{~min}$

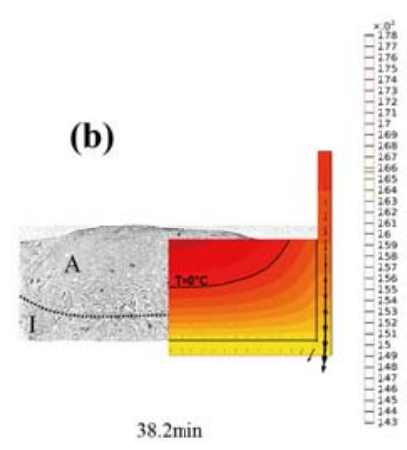

(d)

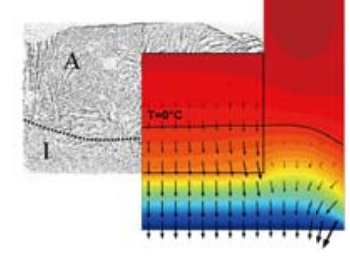

$66.0 \mathrm{~min}$

(f)

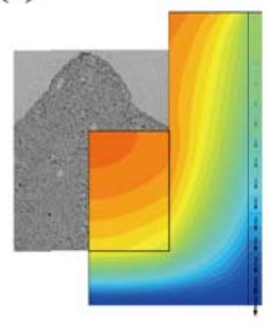

$68.4 \mathrm{~min}$

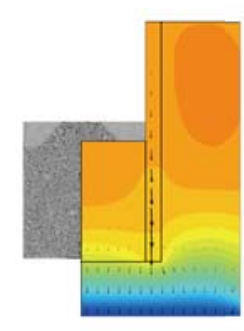

$62.9 \mathrm{~min}$

However, in the other cases, where the temperature of the entire slurry is below the melting temperature, when a nucleation event occurs, an isotropic scaffold architecture is formed, illustrated in moulds 1, 5, and 6 (see Figure 6 (a), (e) and (f)). In these cases, no ice front is formed. Rather, dendritic ice rapidly grows throughout the whole slurry. We can resolve the initial fast growth in our temperature measurements. The slurry in these cases warms up to melting temperature due to the release of latent heat within a few seconds. We integrated the energy that is needed to heat up the entire slurry to $T=0^{\circ} \mathrm{C}$ and estimated how much latent heat had to be released to provide this energy. We conclude that up to $10 \%$ of the slurry crystallises in these first few seconds.

\section{Discussion}

We have shown that by varying the geometry and combination of materials in the moulds, we can change the architecture of the pore structure in the resultant scaffolds which can be predicted from the simulations. Stainless steel moulds lead to fast cooling of the base of the slurry. However, the large mismatch in thermal diffusivity between stainless steel and water/slurry means that in larger moulds, a vertical temperature gradient develops towards the sides of the moulds. Using moulds made from materials with similar thermal diffusivity to water/slurry such as polycarbonate, one can establish mainly horizontal temperature gradients even in larger moulds. However, the cooling rate at the base of the slurry is much lower. 
Our results can be used to design moulds with desired properties for the scaffold. When the entire slurry is well below the melting temperature at the time of nucleation with a small temperature gradient across the slurry, very isotropic scaffolds can be obtained. Small temperature gradients in large moulds can be obtained by an inner metal sleeve inside a polycarbonate mould. In contrast, when parts of the slurry are cooled much faster than others, such as in larger stainless steel moulds, an ice front can develop when part of the slurry is still above the melting temperature and anisotropic pores structures are formed as a result.

Boundary conditions such as cooling rate of the shelf and heat conduction through the surrounding air play a very important role in the cooling process. These parameters can be changed and will affect the temperature contour profile in the slurry. For example, when comparing results for mould 1 in Figure 4 and Figure 6, the influence of cooling rate can be seen. In Table 3, we record the experimentally measured cooling rates which varied between runs due to the variability in thermal contact between the cooling shelf of the freeze dryer and the stainless steel shelf that we use (see Figure 1). The experimentally measured cooling rate in Figure 6 for mould 1 is about 10\% higher than in Figure 4 which was taken from the experiments with mould 3. The faster cooling rate leads to a smaller temperature gradient throughout the slurry.

Table 3. The experimentally measured temperature of the slurry at the base (location 2 in Figure 1), the measured cooling rate of the stainless steel shelf and the time in the simulation when we record a nucleation event

\begin{tabular}{lllll}
\hline Mould & Mould material & $\begin{array}{l}\text { Temperature at base of } \\
\text { slurry }\left({ }^{\circ} \mathbf{C}\right)\end{array}$ & $\begin{array}{l}\text { Cooling rate as measured on } \\
\text { stainless steel shelf }\left({ }^{\circ} \mathbf{C} / \mathbf{m i n}\right)\end{array}$ & $\begin{array}{l}\text { Time of nucleation event } \\
(\mathbf{m i n}) \text { in simulation }\end{array}$ \\
\hline 1 & Stainless steel & -6.8 & -0.90 & 37.2 \\
2 & Stainless steel & -7.0 & -0.89 & 37.8 \\
3 & Polycarbonate & -6.2 & -0.82 & 68.2 \\
4 & Polycarbonate & -4.9 & -0.82 & 66.0 \\
5 & Both & -8.9 & -0.79 & 68.4 \\
\hline 6 & Both & -9.0 & -0.79 & 62.9 \\
\hline
\end{tabular}

We should point out that the comparison in Figure 3 also shows that it is possible to change the cooling rate of the top of the slurry by reducing the heat conduction through the air by, for example, adding a thermal mass such as a glass slide to the top of the mould (leaving a small gap to enable sublimation in the second step of the freeze drying process).

While our simulations capture the physical boundary conditions that determine scaffold architecture, a limitation of our approach remains - that ice growth in the presence of collagen is a highly dynamical system, and the collagen scaffold structure evolves as it grows. We have already shown experimentally in earlier publications ${ }^{[15,32]}$ that annealing during and after growth can change the pore size (but not pore architecture) of the scaffold. To incorporate finer details of pore structures in our simulation, we need to extend our model to include dynamics of ice crystal growth in the presence of collagen. Currently, the phase change model given in COMSOL Multiphysics ${ }^{\circledR}$ ver. 5.0 cannot capture the sudden temperature increase as a result of the very fast initial ice growth, freezing step I (see Figure 1). In addition, the nucleation step is missing from the model. Therefore, the ice growth model in COMSOL Multiphysics ${ }^{\circledR}$ ver. 5.0 results in an incorrect starting point for the resulting slower ice growth freezing step II (see Figure 1). In the future, we plan to implement our own physical description of the process.

The phase transition between ice and water is a first order phase transition, and therefore depends on a nucleation event which is a stochastic event. As can be seen from Table 3, the temperature (here taken as the temperature at base of the mould, the most likely place for nucleation) at which ice nucleates varies between runs. Experimentally, we plan to address this problem by using an external control such as a mechanical perturbation to trigger nucleation. 


\section{Conclusions}

The results show that we can predict from our computer simulation which mould cools the slurry more evenly with less vertical gradients. By changing boundary conditions such as cooling rate and heat conduction through the surrounding air, we can vary the overall temperature gradients in the slurry. Keeping in mind that, without external control, the time of a nucleation event is stochastic, we can calculate the time window in which anisotropic scaffolds are possible and when scaffolds will have isotropic pores. This enables us to design our moulds in a way that maximises the yield of desired pore architecture.

This approach may be transferrable to other freeze-casting procedures that use other templating substances. We will use this result to design moulds with more complex geometries, especially looking into combining mould materials with a range of thermal properties.

\section{Acknowledgements}

The authors thank Samuel Troughton for the design of mould 6. The authors also gratefully acknowledge the financial support of the Newton Trust, the Gates Cambridge Trust and ERC Advanced grant no. 320598 3D-E. A.H. was holding a Daphne Jackson Fellowship, funded by the University of Cambridge, during the time this work was performed.

\section{References}

[1] Zhang H, Cooper AI. Aligned porous structures by directional freezing. Adv. Mater. 2007; 19: 1529-33. http://dx.doi.org/10.1002/adma.200700154

[2] Deville S. Freeze-casting of porous ceramics: A review of current achievements and issues. Adv. Eng. Mater. 2008 ; $10: 155-69$. http://dx.doi.org/10.1002/adem.200700270

[3] Searles J. Freezing and Annealing Phenomena in lyophilization. In: Freeze-Drying/Lyophilization of Pharmaceutical and Biological Products; Rey, L, May, J., Eds.; New York: Marcel Dekker, Inc.; 2004. http://dx.doi.org/10.1201/9780203021323.ch4

[4] Yannas IV, Tzeranis DS, Harley BA, et al. Biologically Active Collagen-Based Scaffolds: Advances in Processing and Characterization. Philos. Trans. R. Soc., A. 2010; 368: 2123-39.

[5] Yoshida S, Kimura Y, Ogino I, et al. Synthesis of a Microhoneycomb-type Silica-Supported Ammonium Molybdophosphate for Cesium Separation. J. Chem. Eng. Jpn. 2013; 46: 616-9. http://dx.doi.org/10.1252/jcej.13we064

[6] Mortera-Blanco T, Mantalaris A, Bismarck A, et al. Long-term Cytokine-free Expansion of Cord Blood Mononuclear Cells in Three-Dimensional Scaffolds. Biomaterials. 2011; 32: 9263-70. PMid:21908041. http://dx.doi.org/10.1016/j.biomaterials.2011.08.051

[7] Mullen LM, Best SM, Brooks RA, et al. Binding and Release Characteristics of Insulin-like Growth Factor-1 from a CollagenGlycosaminoglycan Scaffold. Tissue Eng., Part C. 2010; 16: 1439-48. PMid:20388039.

http://dx.doi.org/10.1089/ten.tec.2009.0806

[8] Campbell JJ, Davidenko N, Caffarel MM, et al. A Multifunctional 3D Co-culture System for Studies of Mammary Tissue Morphogenesis and Stem Cell Biology. Plos One. 2011; 6: 9. PMid:21984937. http://dx.doi.org/10.1371/journal.pone.0025661

[9] Tierney CM, Haugh MG, Liedl J, et al. The effects of collagen concentration and crosslink density on the biological, structural and mechanical properties of collagen-GAG scaffolds for bone tissue engineering. Journal of the Mechanical Behavior of Biomedical Materials. 2009; 2(2): 202-9. http://dx.doi.org/10.1016/j.jmbbm.2008.08.007

[10] Pawelec KM, Wardale J, Best SM, et al. The Effects of Scaffold Architecture and Fibrin Gel Addition on Tendon Cell Phenotype. Journal of Materials Science: Materials in Medicine. 2015; 26(13): 5349. http://dx.doi.org/0.1007/s10856-014 - 5349-3

[11] Kew SJ, Gwynne JH, Enea D, et al. Synthetic Collagen Fascicles for the Regeneration of Tendon Tissue. Acta Biomater. 2012; 8: 3723-31. PMid:22728568. http://dx.doi.org/10.1016/j.actbio.2012.06.018

[12] Grover CN, Cameron RE, Best SM. Investigating the Morphological, Mechanical and Degradation Properties of Scaffolds Comprising Collagen, Gelatin and Elastin for use in Soft Tissue Engineering. J. Mech. Behav. Biomed. Mater. 2012; 10: 62-74, 202. PMid:22520419. http://dx.doi.org/10.1016/j.jmbbm.2012.02.028

[13] Grover CN, Gwynne JH, Pugh N, et al. Crosslinking and Composition Influence the Surface Properties, Mechanical Stiffness and Cell Reactivity of Collagen-Based Films. Acta Biomater. 2012; 8: 3080-90. PMid:22588074.

http://dx.doi.org/10.1016/j.actbio.2012.05.006 
[14] P. Hobbs, Ice Physics, Oxford: Oxford University Press; 1974.

[15] Pawelec KM, Husmann A, Best SM, et al. A Design Protocol for Tailoring Ice-Templated Scaffold Structure. Journal of the Royal Society Interface. 2014; 11. PMid:24402916. http://dx.doi.org/10.1098/rsif.2013.0958

[16] Davidenko N, Gibb T, Schuster C, et al. Biomimetic collagen scaffolds with anisotropic pore architecture. Acta Biomaterialia. 2012; 8: 667-76. PMid:22005330. http://dx.doi.org/10.1016/j.actbio.2011.09.033

[17] Zhang H, Hussain I, Brust M, et al. Aligned two- and three-dimensional structures by directional freezing of polymers and nanoparticles. Nature Materials. 2005; 4(10): 787-93. http://dx.doi.org/10.1038/nmat1487

[18] Muzzio CR, Dini NG. Simulation of freezing step in vial lyophilization using finite element method. Computers \& Chemical Engineering. 2011; 35: 2274-83. http://dx.doi.org/10.1016/j.compchemeng.2010.10.009

[19] Kurz M, Pusztai A, Müller G. Development of a new powerful computer code CrysVUn++ especially designed for fast simulation of bulk crystal growth processes. Journal of Crystal Growth. 1999; 198-9 (Part-1), 101-6.

[20] Zhang N, Park HG, Derby JJ. Simulation of heat transfer and convection during sapphire crystal growth in a modified heat exchanger method. Journal of Crystal Growth. 2013; 367(C): 27-34. http://dx.doi.org/10.1016/j.jcrysgro.2013.01.011

[21] Kirkpatrick RJ. Crystal Growth from the Melt: A Review. American Mineralogist. 1975; 60: 798-814.

[22] Pawelec KM, Husmann A, Best SM. Ice-templated structures for biomedical tissue repair: From physics to final scaffolds. Applied Physics Review. 2014; 1. http://dx.doi.org/10.1063/1.4871083

[23] Deville S, Maire E, Lasalle A, et al. In Situ X-Ray Radiography and Tomography Observations of the Solidification of Aqueous Alumina Particle Suspensions-Part I: Initial Instants. Journal of the American Ceramic Society. 2009; 92(11): $2489-96$. http://dx.doi.org/10.1111/j.1551-2916.2009.03163.x

[24] Vali G, Stansbury EJ. Time-dependent characteristics of the heterogeneous nucleation of ice. Can. J. Phys. 1966; 44: 477-502. http://dx.doi.org/10.1139/p66-044

[25] Agari Y, Ueda A, Omura Y, et al. Thermal diffusivity and conductivity of PMMA/PC blends. Polymer. 1997; 38(4): 801-7. http://dx.doi.org/10.1016/S0032-3861(96)00577-0

[26] Bogaard RH, Desai PD, Li HH, et al. Thermophysical properties of stainless steels. Thermochimica Acta. 1993; $218: 373-93$. http://dx.doi.org/10.1016/0040-6031(93)80437-F

[27] Valvano JW, Cochran JR, Diller KR. Thermal conductivity and diffusivity of biomaterials measured with self-heated thermistors. International Journal of Thermophysics. 1985; 6(3): 301-11. http://dx.doi.org/10.1007/BF00522151

[28] Bejan A, Heat Transfer, John Wiley \& Sons; 1993. p24.

[29] Cooper MG, Mikic BB, Yovanovich MM. Thermal contact conductance. International Journal of Heat and Mass Transfer. 1969; 12(3): 279-300. http://dx.doi.org/10.1016/0017-9310(69)90011-8

[30] Pawelec KM, Husmann A, Best SM, et al. Understanding Anisotropy and Architecture in Ice-Templated Biopolymer Scaffolds Materials Science \& Engineering C. 2014; 37: 141-7. PMid:24582233. http://dx.doi.org/10.1016/j.msec.2014.01.009

[31] Bareggi A, Maire E, Lasalle A, et al. Dynamics of the Freezing Front During the Solidification of a Colloidal Alumina Aqueous Suspension: In Situ X-Ray Radiography, Tomography, and Modeling. Journal of the American Ceramic Society. 2011; 94: 3570-8.

[32] Pawelec KM, Husmann A, Best SM, et al. Altering Crystal Growth and Annealing in Ice-Templated Scaffolds, accepted to be published in Journals of Materials Science. 